\title{
Impact of the Coronavirus Disease (COVID-19) on the Mental Health and Physical Activity of Pharmacy Students at the University of Zambia: A Cross-Sectional Study
}

Steward Mudenda ${ }^{1,2^{*}}$, Moses Mukosha ${ }^{1}$, Chiluba Mwila ${ }^{1}$, Zikria Saleem ${ }^{3}$, Aubrey Chichoni Kalungia ${ }^{1}$, Derick Munkombwe ${ }^{1}$, Victor Daka ${ }^{2,4}$, Bwalya Angel Witika ${ }^{5}$, Martin Kampamba ${ }^{1}$, Misheck Chileshe ${ }^{6}$, Christabel Hikaambo ${ }^{1}$, Maisa Kasanga ${ }^{7}$, Webrod Mufwambi ${ }^{1}$, Ruth Lindizyani Mfune ${ }^{2,4}$, Scott Kaba Matafwali ${ }^{4}$, Angela Gono Bwalya ${ }^{1}$, David Chimbizgani Banda ${ }^{8}$, Akash Gupta $^{9}$, Maureen Nkandu Phiri ${ }^{1}$, Eustarckio Kazonga ${ }^{10}$

${ }^{1}$ University of Zambia, School of Health Sciences, Department of Pharmacy, P.O. Box 50110, Lusaka, Zambia

${ }^{2}$ University of Zambia, School of Veterinary Medicine, Department of Disease Control, P.O Box 32379, Lusaka, Zambia

${ }^{3}$ Department of Pharmacy Practice, Faculty of Pharmacy, the University of Lahore, Lahore, Pakistan

${ }^{4}$ Copperbelt University, Michael Chilufya Sata School of Medicine, P.O Box 71769, Ndola, Zambia

${ }^{5}$ Department of Pharmacy, DDT College of Medicine, P.O Box 70587, Gaborone, Botswana

${ }^{6}$ Mary Begg Health Services, 56 Chintu Avenue, Northrise, P.O Box 72221, Ndola, Zambia

${ }^{7}$ Zhengzhou University, College of Public Health, 100 Kexue Avenue, Zhengzhou, Henan 450001, China

${ }^{8}$ Chreso University, Department of Nursing, Lusaka, Zambia

${ }^{9}$ Ramniranjan Jhunjhunwala College, Affiliated with University of Mumbai, Department of Management Studies, 400086, Ghatkopar, Mumbai, India

${ }^{10}$ University of Lusaka, School of Medicine and Health Sciences, Department of Public Health, P.O. Box 36711, Lusaka, Zambia

*Corresponding author: Steward Mudenda, University of Zambia, School of Health Sciences, Department of Pharmacy, P.O Box 50110, Lusaka, Zambia, Phone Number: +260977549974. Email: freshsteward@gmail.com 


\begin{abstract}
Background: The novel coronavirus disease (COVID-19) is a serious global health problem that has negatively impacted the mental health of students.

Methods: We conducted an online descriptive cross-sectional study among 273 undergraduate pharmacy students at the University of Zambia. A partial proportional odds regression model was used to determine the predictors of anxiety. All statistical tests were set at $95 \%$ confidence level $(\mathrm{p}<0.05)$.

Results: A response rate of $70 \%$ was obtained with the majority of the students being female $51.6 \%$. Of the 273 respondents, $23.8 \%$ did not experience anxiety, $34.4 \%$ experienced mild anxiety, $24.9 \%$ experienced moderate anxiety while $16.9 \%$ experienced severe anxiety about COVID-19. It was also found that $61.2 \%$ of students reported that their attention to mental health increased during the COVID-19 pandemic whereas $44.3 \%$ reported an increased resting time with a significant reduction in relaxation $51.3 \%$ and physical activity $45.4 \%$ time. Factors that affected mental health included; reduced family care (OR: 2.27; 95\% CI: 1.09-4.74 ), not changing attention to mental health (OR: 0.33 ; 95\% CI: $0.18-0.62)$, being in the final year of study (OR: 0.33 ; 95\% CI: 0.13-0.84), reduced time of resting (OR: 2.10; 95\% CI: 1.26-3.50) and feeling helpless (OR: 0.42; 95\% CI:0.23-0.75).

Conclusion: COVID-19 negatively impacted the mental health and physical activity of pharmacy students at the University of Zambia. This can have negative health and academic outcomes for students going forward. Higher learning institutions and key stakeholders should implement measures to aid students to recover from the impact of COVID-19 on their mental health and physical activity.
\end{abstract}

Keywords: Coronavirus disease, COVID-19, mental health, physical activity, pharmacy students, anxiety 
medRxiv preprint doi: https://doi.org/10.1101/2021.01.11.21249547; this version posted January 13, 2021. The copyright holder for this preprint (which was not certified by peer review) is the author/funder, who has granted medRxiv a license to display the preprint in perpetuity.

It is made available under a CC-BY-NC 4.0 International license.

\section{Introduction}

The novel coronavirus disease (COVID-19) originated from Wuhan city, Hubei province of China [1], with 27 cases of pneumonia of unknown cause identified on $31^{\text {st }}$ December 2019 $[2,3]$. The causative agent of this infection was later named Severe Acute Respiratory Syndrome Coronavirus 2 (SARS-CoV-2) [2,4,5]. This led to the naming of the disease as COVID-19 [6]. The main clinical presentations of patients suffering from COVID-19 at that time included dry cough, sore throat, chest pain, dyspnoea, headache, fever, nausea, vomiting, diarrhoea, bilateral lung infiltration on imaging, and abnormal radiological findings [7-10]. Current findings have reported clinical features such as myalgias, fatigue, abdominal pain, tachycardia, tachypnea, and hypotension [11]. COVID-19 was declared a global pandemic by the World Health Organization (WHO) on $11^{\text {th }}$ March 2020 due, in part, to its rapid spread across the globe and relatively high mortality rate among specific populations [6,12-14]. As a result, many countries instituted lockdowns to prevent further spreading of COVID-19 [15,16].

There is strong evidence suggesting that COVID-19 has had adverse effects on the mental wellbeing of individuals worldwide [17-21]. Some of the mental health problems observed were illness anxiety disorder (IAD or formerly hypochondriasis), helplessness and horror, and the fear of COVID-19 associated stigmatization [22-25]. Besides, some populations have reportedly experienced psychological impacts including but not limited to; depression, anxiety, stress, and mood swings due to the pandemic [18,22,26-29].

Some studies have shown that there is a positive relationship between physical activity and mental health [30]. Physical activity plays a significant role in reducing the symptoms of mental health illnesses [31]. Lockdowns and restrictions to movement during the COVID-19 pandemic have affected the time that people spend resting, relaxing, and exercising [32,33]. Many people experienced changes in their usual day-to-day routines, including physical activity, and that may have contributed to mental health disorders in most populations [34].

As of $1^{\text {st }}$ December 2020, the number of COVID-19 cases in Zambia was approximated at 17,647 with 357 deaths [35]. The rapid spread of COVID-19 and aforementioned lockdowns led to the closure of schools, colleges, and universities worldwide [36,37]. This was done to prevent further transmission and spread of the virus [12,38]. Unfortunately, the closure of learning 
institutions has been reported to negatively affect the mental health and academic life of students $[39,40]$. Many youths, the population of which the majority of the students comprises, have experienced mental health problems due to COVID-19 [39]. Recent studies have reported that students have experienced symptoms of anxiety, depression, stress, panic, and mood swings due to COVID-19 and its negative effects on the education system [41-43]. This may in turn affect the academic performance of the students compared to their performance before the COVID-19 era $[44,45]$. COVID-19 has disrupted many educational and extracurricular activities for students $[43,46,47]$. However, most of the impacts of COVID-19 on academic performance will be known during the post-COVID-19 era.

A literature search did not yield previous studies on the impact of COVID-19 on the mental health and physical activity of students and other populations in Zambia. Thus, as an initial step, we assessed the impact of COVID-19 on the mental health and physical activity of undergraduate pharmacy students at the University of Zambia (UNZA) and reported them vide infra. This was against a background that training of pharmacists in Zambia has over the years largely been utilising traditional face-to-face teaching and learning, including experiential learning in pre-clinical and clinical subject areas [48]. The restrictions and health risks imposed by COVID-19 presented unique challenges not only for the facilitation of learning in schools and universities but also to psychosocial wellbeing of the learners. Therefore, our study aimed to assess the impact of COVID-19 on the mental health and physical activity of undergraduate pharmacy students at the University of Zambia.

\section{Methods}

\section{Study Design, Participants and Sampling}

This was a descriptive cross-sectional study involving the undergraduate pharmacy students at UNZA - the largest and leading public university in Zambia. Thus, the results of this study gave an insight into the mental health and physical activity impact of COVID-19 on pharmacy students. The study included all the enrolled cohorts of undergraduate pharmacy students at UNZA, School of Health Sciences, that provided consent to take part in the study during the academic year 2019 to 2020. UNZA is currently the major producer of Bachelor of Pharmacy 
graduates in Zambia [48]. Undergraduate pharmacy students without access to the online questionnaire were excluded from the study.

The study population was 410 pharmacy students, determined as follows: a sum of 90 second year, 140 third year, 126 fourth year, and 54 fifth-year pharmacy students, cumulatively.

The sample size was determined using Yamane's formula; $\mathrm{n}=\frac{N}{1+N(e)^{2}}$ [49]. A margin of error of $5 \%$ and a population of 410 were used. A $10 \%$ loss or non-response was anticipated. However, 288 students responded representing a response rate of $70 \%$. From the 288 pharmacy students, a total of 273 students managed to complete the questionnaire. 15 students did not complete responding to the questionnaire.

\section{Data Collection Tool}

Data were collected using an online self-administered questionnaire that was adapted from similar studies $[39,41,50]$. Firstly, the questionnaire was circulated to experts from the University of Zambia to allow for content and face validation. The modified questionnaire was pre-tested among 10 undergraduate pharmacy students at UNZA, who, later were excluded from the main study. Student's anxiety was measured using the generalised anxiety disorder 7-item (GAD-7) scale developed by Spitzer et al., [51]. The GAD-7 scale is used to categorize anxiety into four classes, namely; no anxiety, mild, moderate, and severe anxiety. Scoring of GAD-7 anxiety levels was done from 0 to 21 and categorised as follows; 1-4 no anxiety, 5-9 mild anxiety, 10-14 moderate anxiety, and 15-21 severe anxiety. The questionnaire was used to collect data on sociodemographic characteristics and mental health and physical activity impacts of COVID-19 on undergraduate pharmacy students from $1^{\text {st }}$ August to $30^{\text {th }}$ September 2020.

\section{Study outcome}

Mental health: we evaluated mental health using the four levels of anxiety disorders from the GAD-7 anxiety levels as follows

$$
\mathrm{Y}=\left\{\begin{array}{l}
1 \text { if the score } 15-25 \text { (severe anxiety) } \\
2 \text { if the score } 10-14 \text { (moderate anxiety) } \\
3 \text { if the score 5-9 (mild anxiety) } \\
4 \text { if the score } 0-4 \text { (no anxiety) }
\end{array}\right.
$$


medRxiv preprint doi: https://doi.org/10.1101/2021.01.11.21249547; this version posted January 13, 2021. The copyright holder for this preprint (which was not certified by peer review) is the author/funder, who has granted medRxiv a license to display the preprint in perpetuity.

It is made available under a CC-BY-NC 4.0 International license .

\section{Data Analysis}

Data were analysed using Stata/IC version 16 (Stata Corp., College Station, Texas, USA). The significance level was set at alpha 0.05 and $95 \%$ confidence intervals.

For descriptive statistics, the median (interquartile range [IQR]) for continuous values (i.e age) was calculated after testing for the assumption of normality using Shapiro-Wilk W-test and graphically qq-plots. For the comparison of baseline characteristics across levels of anxiety, we used the Kruskal Wallis test and Pearson chi-square test or Fisher's exact test were appropriate

In order to choose a model to identify independent predictors of anxiety as a response with four ordered categories. firstly the confounders to be included in the model were found by carrying out backward elimination using the socio-demographic variables as candidates with a liberal pvalue (0.20) for exclusion, in order to ensure that all possible confounders were included. After carrying out the backward elimination, forward selection (with the same liberal P-value of 0.20 for inclusion) was carried out to see whether any other possible confounders would be identified. In this case, both backward elimination and forward selection identified the same model.

To get some idea of the effect of academic, social and family support factors, Proportional Odds Models (POM) were then fitted for each of the factors separately, adjusting for the sociodemographic variables that had been identified. Thereafter backward elimination was carried out with a stricter $\mathrm{P}$-value for the exclusion of $\mathrm{p}=0.10$ with age fixed in the model, irrespective of whether it was still statistically significant or not. The model was then refitted and tested for proportional odds assumption using the brant test. The model was found to be violating the proportional odds assumption and therefore a partial Proportional Odds Model (PPOM) was fitted. Each model's fit was evaluated using the deviance test as well as the log-likelihood and the pseudo R2.

\section{Ethical Considerations}

This study was approved by the University of Zambia Health Sciences Research Ethics Committee (UNZAHSREC). Protocol ID: 2020310174. IORG no: 0009227 IRB no: 00011000

FWA no: 00026270. After IRB ethical approval, regulatory approval was obtained from the National Health Research Authority (NHRA). 


\section{Results}

\section{Socio-demographic characteristics of study participants}

The baseline characteristics of respondents by levels of anxiety are shown in table 1. A total of 273 respondents with a median age of 24 years (IQR, 22-27) were included in the analysis. From the total, about 65 (23.8\%) had no anxiety, 94 (34.4\%) had mild anxiety, 68 (24.9\%) hard moderate anxiety and $46(16.9 \%)$ had severe anxiety. There were more females than males 141 (51.6\%). The majority were single $225(82.4 \%)$, were in the third year of study $113(41.4 \%)$, lived in urban areas $156(57.1 \%)$, lived with parents $178(65.2 \%)$ and were unemployed 196 (71.8\%). From the univariate analysis, there was evidence of a difference in residence $(\mathrm{P}=0.005)$, marital status $(\mathrm{p}=0.024)$ and whether or not a respondent was living with their parents $(\mathrm{P}=0.022)$, across all the levels of anxiety.

\section{Academic life, social networks and family support by levels of anxiety}

Table 2 shows the academic life, social networks and family support by levels of anxiety. We noted that there were more respondents with no steady income 187 (68.5\%), with reduced social support from family 118 (43.5\%), with reduced social support from friends 182 (66.7\%), who were feeling helpless 189 (69.2\%), had increased resting time 120 (44\%), with reduced relaxation time 140 (51.3\%), with reduced academic performance $221(81 \%)$ and with reduced physical activity 124 (45.4\%). Across all levels of anxiety, there was a statistically significant difference in steady income $(p=0.014)$, social support from family ( $\mathrm{p}=<0.0001)$, social support from friends $(\mathrm{p}=0.026)$, helpless $(\mathrm{p}=<0.0001)$, resting time $(\mathrm{p}=0.001)$, relaxing time $(\mathrm{p}=0.002)$, academic performance $(\mathrm{p}<0.0001)$ and exercise $(\mathrm{p}=0.017)$.

\section{Factors affecting the mental health of undergraduate pharmacy students}

Table 3 shows the results of the Partial Proportional Odds regression Model (PPOM). The loglikelihood ratio chi-square test $\operatorname{LRX}^{2}(19)=95.77$, $\mathrm{p}<0.0001$ for this model indicates that the full model shows a better fit than the null model with no independent variables in predicting the levels of anxiety. The Wald test of parallel lines assumption for the final model: Chi-square test $=29.27, \mathrm{df}=32, \mathrm{p}=0.606$ indicates that the final model does not violet the proportional odds assumption. Since academic performance violates the PO assumption its effect was allowed to vary across the three binary models. 
This model indicated that the factors associated with levels of anxiety among the respondents were reduced care from family, not changing attention to one's mental health, being in the final year of study, reduced time of resting and feeling helpless.

Compared to increased family care, those who reported receiving reduced family care (aOR: 2.27, 95\% CI: 1.09-4.74, p=0.029) and reduced resting time (aOR: 2.10, 95\% CI:1.26-3.50, $\mathrm{p}=0.005$ ) were $27 \%$ and $10 \%$ more likely to be in higher levels of anxiety (i.e severe anxiety) respectively adjusting for all covariates. The respondents who were in their final year of studies compared to the second year (aOR:0.33, 95\% CI: 0.13-0.84, $\mathrm{p}=0.020$ ) and those not feeling helpless (aOR: 0.42, 95\% CI: 0.23-0.75) were 67\% and 58\% less likely to be in higher levels of anxiety respectively when holding other covariates constant. Meanwhile, a unit increase in age was associated with increased odds of being beyond a particular category of anxiety (higher category) by a factor of 1.04 though we could not rule out random chance finding $(\mathrm{p}=0.142)$. Overall academic performance (i.e reduced compared to increased) was associated with $81 \%$ and $40 \%$ increase in the likelihood of a respondent being in higher levels of anxiety for the first (95\% CI: 3.12-30.88, $\mathrm{p}<0.0001)$ and second (95\% CI: 1.23-13.28, $\mathrm{p}=0.021)$ binary models. On the contrary, we noted a $27 \%$ reduced likelihood of being in higher levels of anxiety across the third binary model (95\% CI: $0.57-7.45)$ but this was not statistically significant $(\mathrm{p}=0.266)$. 


\section{Discussion}

We assessed the impact of COVID-19 pandemic on the mental health and physical activity of undergraduate pharmacy students at the University of Zambia. We found that the factors associated with levels of anxiety among the students were reduced care from family, not changing attention to one's mental health, being in the final year of study, reduced time of resting and feeling helpless. Currently, COVID-19 has caused many negative impacts on the education sector and other sectors across the globe.

\section{Mental health}

Our study established that COVID-19 has affected the mental health of pharmacy students and reduced their time to do physical activity. Though this was expected, it is the magnitude of the impact on mental health that is noteworthy. Our study found that $76.2 \%$ of the students experienced the anxiety of which the majority (34.4\%) had experienced mild anxiety. Our survey further found that many students felt helpless (69.2\%) as a result of the COVID-19 pandemic spreading in Zambia. Previous studies have also reported that COVID-19 affects the mental health of students. A study in China reported that most of the students (21.3\%) experienced mild anxiety [41]. Another study in China reported overall anxiety of $26.0 \%$ with the majority of the students $(23.2 \%)$ experiencing mild anxiety [52]. The study further reported that students had experienced depression due to the impact of COVID-19 [52]. Xiao et al.reported that anxiety prevalence among medical students was $17.1 \%$ and depression was $25.3 \%$ [53]. In Bangladesh, Khan et al.(2020) reported that $33.3 \%$ of the students experienced anxiety [54]. Further, other mental health disorders such as depression, stress, and event-specific distress were reported. Similarly, in Pakistan, Waseem et al. (2020) reported that 53.0\% of undergraduate medical students experienced stress as a result of COVID-19 [42]. Our survey and other similar studies reported that students experienced mental health problems associated with COVID-19. However, the prevalence of mental health problems reported in our study is higher than the ones reported in similar studies. This difference could be because our setting is resource-constrained. Also, the prevalence of anxiety in our study may have been higher since the pharmacy students experienced online learning for the first time.

The mental health problems reported in our study were mainly associated with reduced care from family members, not changing attention to one's mental health, being in the final year of study, 
reduced time of resting and feeling helpless. Similar studies reported that mental health problems could have been affected by factors such as fear of contracting the virus [55], social distancing [53], economic impacts of COVID-19 [56], fear of delayed academic progression [41], fear of poor academic performance [45], and impact of COVID-19 on family and social networks [39].

Mental health problems associated with COVID-19 have been reported in different populations including healthcare workers [57,58] and the general population [59]. Therefore, this indicates that COVID-19 has impacted the mental health of different populations of people.

\section{Physical activity and mental health}

In this survey, the majority of the students' attention to mental health (61.2\%) and time to rest (44.3\%) has increased as a result of COVID-19. However, most of the students reported that their time to relax $(51.3 \%)$ and exercise $(45.4 \%)$ had reduced. It was found that the students spent more time resting, but very little time relaxing and exercising. Physical activity has been linked to the improved mental health of human beings [60-63]. Additionally, physical activity reduces mental health problems such as anxiety, depression, social withdrawal, low self-esteem, and mood swings [64,65]. Even minimal physical activities while staying at home can be performed so that individuals remain active during the pandemic [66,67]. However, due to COVID-19, preventive measures such as social distancing and restrictions in movements meant that students spent their time at home and had no access to physical exercising facilities like a gymnasium. This caused their resting time to increase while the exercising time reduced and thus may have resulted in anxiety. Similarly, other studies reported that there has been a significant reduction in physical activity as a result of quarantine $[61,66,68]$. This reduction in physical activities is one of the contributing factors to the reported mental health problems due to COVID-19. There is evidence that indicates that reduced physical activity increases the risks of mental health problems among students [64]. Since many schools, colleges, and Universities are now open in Zambia, students must practice simple exercises while observing the preventive measures of COVID-19.

\section{Implications on educational policy and practice}

The importance of good mental health and wellbeing in cognitive development cannot be understated. With existing evidence showing that the majority of undergraduate pharmacy 
students at UNZA predominantly utilise a strategic approach to learning - an attribute characterised by a focus on achieving and fear of failure [48], it was a cause for concern that the negative impacts of COVID-19 on the mental health of students could further affect their cognitive development, approaches to learning, and academic outcomes. We, therefore, argue that that educational policy and practice amidst the COVID-19 pandemic and beyond should consider adopting an instructional design that influences and enhances mental resilience in addition to the attainment of meaningful learning outcomes, critical thinking and effective study skills among pharmacy students [48]. We further contend that in addition to modifying the above facets of the learning environment at the university, extra consideration should be given to provide psychosocial support to students negatively affected by the COVID-19 pandemic.

\section{Strengths and limitations of the Study}

This is the first study to assess the impact of COVID-19 on the mental health and physical activity among Zambian students and it has highlighted the need to pay attention to the mental health of students not only during COVID-19 pandemic but even beyond. Further, the study did not only indicate the prevalence of anxiety among pharmacy students due to COVID-19, but it also explored the factors that independently predict the anxiety levels among these students.

Since we conducted the study among pharmacy students, the results cannot be generalised to other students doing different programmes. The online nature of the study meant that certain students had no access to the questionnaire and were, therefore, not part of the study. The study findings may not represent the future academic outcomes of undergraduate pharmacy students.

\section{Conclusion}

This study found that the COVID-19 negatively impacted the mental health and physical activity of undergraduate pharmacy students at the University of Zambia. Our study established that students experiencing anxiety associated with COVID-19 risk were more likely to have poor academic outcomes and progression. Institutions of higher learning and other stakeholders must, therefore, put in place measures to mitigate the negative impact of COVID-19 on the mental health and academic life of students. We will continue to monitor this and other post-COVID-19 effects on educational processes and outcomes in future. 


\section{What is known about this topic}

- Literature search indicates that students from various countries and pursuing different programmes have been experiencing anxiety associated with COVID-19.

- COVID-19 has impacted the education sector and other sectors negatively.

\section{What this study adds}

- This study adds valuable information to existing knowledge on the possible impact of COVID-19 on the mental health and physical activity of students.

- The study adds basic information on COVID-19 vs mental health and COVID-19 vs physical activity.

- This study also adds information on the imapact of COVD-19 on academic progression and performance of students, and thus calls for schools and key stakeholders to provide measures that will help students recover from the negative impact of COVID-19.

\section{Acknowledgements}

The authors are grateful to all the pharmacy students who took their time to participate in this study. We are also grateful to the University of Zambia Library for providing access to the majority of the articles that were used in this study. We thank the following individuals for helping in editing the manuscript; Dr. Jimmy Hangoma, Mr. Moses Ngazimbi, Mr. Frank Mudenda, Ms. Dainess Hang'andu, Mr. Paul Masebe, and Mr. Edgar John Sintema.

\section{Competing interests}

Conflict of interest: All authors declared no competing conflict of interest.

Funding: This study received no external funding.

\section{Authors' contributions}

SM conceptulaized the study. Data collection was done by SM, MNP, and CM. Data analysis was conducted by SM, MM, MC, VD, and EK. All authors (SM, MM, CM, XS, ACK, DM, BAW, VD, RLM, MC, MK, AGB, DCB, MK, CH, SKM, AG, WM, MNP, and EK) contributed to data interpretation and writing of the initial manuscript. All authors reviewed the intellectual content of the manuscript. All authors read and reviewed the materials cited in this manuscript. 
Project administration and supervision was done by SM. All authors read and approved the final version of the manuscript.

\section{References}

1. Cascella M, Rajnik M, Cuomo A, Dulebohn SC, Di Napoli R. Features, Evaluation and Treatment Coronavirus (COVID-19). StatPearls. StatPearls Publishing; 2020.

2. Lu H, Stratton CW, Tang YW. Outbreak of pneumonia of unknown etiology in Wuhan, China: The mystery and the miracle. Vol. 92, Journal of Medical Virology. John Wiley and Sons Inc.; 2020. p. 401-2.

3. Bogoch II, Watts A, Thomas-Bachli A, Huber C, Kraemer MUG, Khan K. Pneumonia of unknown aetiology in Wuhan, China: Potential for international spread via commercial air travel. J Travel Med. 2020;27(2).

4. Zhong BL, Luo W, Li HM, Zhang QQ, Liu XG, Li WT, et al. Knowledge, attitudes, and practices towards COVID-19 among chinese residents during the rapid rise period of the COVID-19 outbreak: A quick online cross-sectional survey. Int J Biol Sci. 2020;16(10):174552.

5. Hangoma JM, Mudenda S, Mwenechanya MM, Kalungia AC. Community pharmacists' knowledge and preparedness to participate in the fight against Coronavirus disease 2019 (COVID-19) in Zambia. medRxiv. 2020;2020.09.01.20185694.

6. Sohrabi C, Alsafi Z, O'Neill N, Khan M, Kerwan A, Al-Jabir A, et al. World Health Organization declares global emergency: A review of the 2019 novel coronavirus (COVID-19). Vol. 76, International Journal of Surgery. Elsevier Ltd; 2020. p. 71-6.

7. Guan W, Ni Z, Hu Y, Liang W, Ou C, He J, et al. Clinical characteristics of coronavirus disease 2019 in China. N Engl J Med. 2020;382(18):1708-20.

8. Huang C, Wang Y, Li X, Ren L, Zhao J, Hu Y, et al. Clinical features of patients infected with 2019 novel coronavirus in Wuhan, China. Lancet. 2020;395(10223):497-506.

9. Mudenda S. Letter to Editor: Coronavirus Disease (COVID-19): A Global Health Problem. Int J Pharm Pharmacol. 2020;4(1):1-2. 
10. Phiri, NM, Banda, M, Mudenda, S, Ngazimbi, M, Hangoma, JM, Mufwambi, W, Mutati, RK, Muungo L. Coronavirus Disease 2019 (COVID-19): The Role of Pharmacists in the Fight against COVID-19 Pandemic. Int J Pharm Pharmacol. 2020;4(1):1-3.

11. Shah SJ, Barish PN, Prasad PA, Kistler A, Neff N, Kamm J, et al. Clinical features, diagnostics, and outcomes of patients presenting with acute respiratory illness: A retrospective cohort study of patients with and without COVID-19. EClinicalMedicine. 2020;27:100518.

12. Kasanga M, Mudenda S, Gondwe T, Chileshe M, Solochi B, Wu J. Impact of COVID-19 on blood donation and transfusion services at Lusaka provincial blood transfusion centre, Zambia. Pan Afr Med J. 2020;35(2):74.

13. Chileshe M, Mulenga D, Mfune RL, Nyirenda TH, Mwanza J, Mukanga B, et al. Increased number of brought-in-dead cases with COVID-19: is it due to poor health-seeking behaviour among the Zambian population? Pan Afr Med J. 2020;37:136.

14. Cucinotta D, Vanelli M. WHO declares COVID-19 a pandemic. Vol. 91, Acta Biomedica. Mattioli 1885; 2020. p. 157-60.

15. Atalan A. Is the lockdown important to prevent the COVID-9 pandemic? Effects on psychology, environment and economy-perspective. Ann Med Surg. 2020;56:38-42.

16. Lau H, Khosrawipour V, Kocbach P, Mikolajczyk A, Schubert J, Bania J, et al. The positive impact of lockdown in Wuhan on containing the COVID-19 outbreak in China. J Travel Med. 2020;27(3).

17. Luo M, Guo L, Yu M, Wang H. The psychological and mental impact of coronavirus disease 2019 (COVID-19) on medical staff and general public - A systematic review and meta-analysis. Vol. 291, Psychiatry Research. Elsevier Ireland Ltd; 2020. p. 113190.

18. Tee ML, Tee CA, Anlacan JP, Aligam KJG, Reyes PWC, Kuruchittham V, et al. Psychological impact of COVID-19 pandemic in the Philippines. J Affect Disord. 2020;277:379-91.

19. Aga SS, Khan MA, Nissar SS, Banday MZ. [Assessment of Mental Health and Various Coping Strategies among general population living Under Imposed COVID-Lockdown Across 
world: A Cross-Sectional Study]. Ethics, Med public Heal. 2020;100571.

20. Wang H, Xia Q, Xiong Z, Li Z, Xiang W, Yuan Y, et al. The psychological distress and coping styles in the early stages of the 2019 coronavirus disease (COVID-19) epidemic in the general mainland Chinese population: A web-based survey. Hashimoto K, editor. PLoS One. 2020;15(5):e0233410.

21. Mukhtar S. Psychological health during the coronavirus disease 2019 pandemic outbreak. Vol. 66, International Journal of Social Psychiatry. SAGE Publications Ltd; 2020. p. 512-6.

22. Alkhamees AA, Alrashed SA, Alzunaydi AA, Almohimeed AS, Aljohani MS. The psychological impact of COVID-19 pandemic on the general population of Saudi Arabia. Compr Psychiatry. 2020;102(10):152192.

23. Sun N, Wei L, Shi S, Jiao D, Song R, Ma L, et al. A qualitative study on the psychological experience of caregivers of COVID-19 patients. Am J Infect Control. 2020;48(6):592-8.

24. Lu W, Wang H, Lin Y, Li L. Psychological status of medical workforce during the COVID19 pandemic: A cross-sectional study. Psychiatry Res. 2020;288.

25. Peprah P, Gyasi RM. Stigma and COVID-19 crisis: A wake-up call. International Journal of Health Planning and Management. John Wiley and Sons Ltd; 2020.

26. Wang C, Pan R, Wan X, Tan Y, Xu L, Ho CS, et al. Immediate psychological responses and associated factors during the initial stage of the 2019 coronavirus disease (COVID-19) epidemic among the general population in China. Int J Environ Res Public Health. 2020;17(5):3.

27. Qiu J, Shen B, Zhao M, Wang Z, Xie B, Xu Y. A nationwide survey of psychological distress among Chinese people in the COVID-19 epidemic: Implications and policy recommendations. Vol. 33, General Psychiatry. BMJ Publishing Group; 2020.

28. Wang C, Pan R, Wan X, Tan Y, Xu L, McIntyre RS, et al. A longitudinal study on the mental health of general population during the COVID-19 epidemic in China. Brain Behav Immun. 2020;87:40-8.

29. Temsah MH, Al-Sohime F, Alamro N, Al-Eyadhy A, Al-Hasan K, Jamal A, et al. The 
psychological impact of COVID-19 pandemic on health care workers in a MERS-CoV endemic country. J Infect Public Health. 2020;13(6):877-82.

30. Stanton R, Happell B, Reaburn P. The mental health benefits of regular physical activity, and its role in preventing future depressive illness. Nurs Res Rev. 2014;4:45.

31. Pascoe M, Bailey AP, Craike M, Carter T, Patten R, Stepto N, et al. Physical activity and exercise in youth mental health promotion: A scoping review. Vol. 6, BMJ Open Sport and Exercise Medicine. BMJ Publishing Group; 2020. p. 677.

32. Ding D, Del Pozo Cruz B, Green MA, Bauman AE. Is the COVID-19 lockdown nudging people to be more active: a big data analysis. Vol. 54, British Journal of Sports Medicine. BMJ Publishing Group; 2020. p. 20.

33. Javed B, Sarwer A, Soto EB, Mashwani Z ur R. The coronavirus (COVID-19) pandemic's impact on mental health. Int J Health Plann Manage. 2020;35(5):993-6.

34. Srivastav AK, Sharma N, Samuel AJ. Impact of Coronavirus disease-19 (COVID-19) lockdown on physical activity and energy expenditure among physiotherapy professionals and students using web-based open E-survey sent through WhatsApp, Facebook and Instagram messengers: Impact of COVID-19 lock. Clin Epidemiol Glob Heal. 2020;

35. WHO. Zambia: WHO Coronavirus Disease (COVID-19) Dashboard | WHO Coronavirus Disease (COVID-19) Dashboard. 2020.

36. Mudenda S, Zulu A, Phiri MN, Ngazimbi M, Mufwambi W, Kasanga M, et al. Impact of Coronavirus Disease 2019 (COVID-19) on College and University Students: A Global Health and Education Problem. Aquademia. 2020;4(2):ep20026.

37. Sintema EJ. E-Learning and Smart Revision Portal for Zambian Primary and Secondary School Learners: A Digitalized Virtual Classroom in the COVID-19 Era and Beyond. Aquademia. 2020;4(2):ep20017.

38. Toquero CM. Challenges and Opportunities for Higher Education amid the COVID-19 Pandemic: The Philippine Context. Pedagog Res. 2020;5(4):em0063. 
39. Liang L, Ren H, Cao R, Hu Y, Qin Z, Li C, et al. The Effect of COVID-19 on Youth Mental Health. Psychiatr Q. 2020;91(3):841-52.

40. Zhai Y, Du X. Addressing collegiate mental health amid COVID-19 pandemic. Vol. 288, Psychiatry Research. Elsevier Ireland Ltd; 2020.

41. Cao W, Fang Z, Hou G, Han M, Xu X, Dong J, et al. The psychological impact of the COVID-19 epidemic on college students in China. Psychiatry Res. 2020;287(5):112934-40.

42. Waseem M, Aziz N, Arif MU, Noor A, Mustafa M, Khalid Z. Post-Traumatic Stress of COVID-19 Pak Armed Forces Med. Vol. 70, J. COVID; 2020.

43. Gupta A, Goplani M. Impact of COVID-19 on Educational Institution in India. 2020. p. 5.

44. Sahu P. Closure of Universities Due to Coronavirus Disease 2019 (COVID-19): Impact on Education and Mental Health of Students and Academic Staff. Cureus. 2020;12(4):4.

45. Sintema EJ. Effect of COVID-19 on the performance of grade 12 students: Implications for STEM education. Eurasia J Math Sci Technol Educ. 2020;16(7):em1851.

46. Billy M. The Influence of Dynamic Organizations and the Application of Digital Innovations to Educational Institutions in the World during the COVID-19 Pandemic. SSRN Electron J. 2020;36(3):9.

47. Lee J. Mental health effects of school closures during COVID-19. Lancet Child Adolesc Heal. 2020;4(6):421.

48. Kalungia AC, Tyson Muungo L, Marshall S, Apampa B, May C, Munkombwe D. Training of pharmacists in Zambia: Developments, curriculum structure and future perspectives. Pharm Educ. 2019;19(1):69-78.

49. Joskow J, Yamane T. Statistics, an Introductory Analysis. J Am Stat Assoc. 1965;60(310):678.

50. Zhang Y, Ma ZF. Impact of the COVID-19 pandemic on mental health and quality of life among local residents in Liaoning Province, China: A cross-sectional study. Int J Environ Res Public Health. 2020;17(7). 
51. Spitzer RL, Kroenke K, Williams JBW, Löwe B. A brief measure for assessing generalized anxiety disorder: The GAD-7. Arch Intern Med. 2006;166(10):1092-7.

52. Chang J, Yuan Y, Wang D. Mental health status and its influencing factors among college students during the epidemic of COVID-19. Nan Fang Yi Ke Da Xue Xue Bao. 2020;40(2):1716.

53. Xiao H, Shu W, Li M, Li Z, Tao F, Wu X, et al. Social distancing among medical students during the 2019 coronavirus disease pandemic in china: Disease awareness, anxiety disorder, depression, and behavioral activities. Int J Environ Res Public Health. 2020;17(14):1-13.

54. Khan AH, Sultana MS, Hossain S, Hasan MT, Ahmed HU, Sikder MT. The impact of COVID-19 pandemic on mental health \& wellbeing among home-quarantined Bangladeshi students: A cross-sectional pilot study. J Affect Disord. 2020;277:121-8.

55. Brooks SK, Webster RK, Smith LE, Woodland L, Wessely S, Greenberg N, et al. The psychological impact of quarantine and how to reduce it: rapid review of the evidence. Vol. 395, The Lancet. Lancet Publishing Group; 2020. p. 912-20.

56. Evans O. Socio-economic impacts of novel coronavirus: The policy solutions. BizEcons Q. 2020;7(March):3-12.

57. Tan BYQ, Chew NWS, Lee GKH, Jing M, Goh Y, Yeo LLL, et al. Psychological Impact of the COVID-19 Pandemic on Health Care Workers in Singapore. Vol. 173, Annals of internal medicine. NLM (Medline); 2020. p. 317-20.

58. Kang L, Li Y, Hu S, Chen M, Yang C, Yang BX, et al. The mental health of medical workers in Wuhan, China dealing with the 2019 novel coronavirus. Vol. 7, The Lancet Psychiatry. Elsevier Ltd; 2020. p. e14.

59. Torales J, O’Higgins M, Castaldelli-Maia JM, Ventriglio A. The outbreak of COVID-19 coronavirus and its impact on global mental health. Vol. 66, International Journal of Social Psychiatry. SAGE Publications Ltd; 2020. p. 317-20.

60. Sharma A, Madaan V, Petty FD. Exercise for mental health [1]. Vol. 8, Primary Care Companion to the Journal of Clinical Psychiatry. Physicians Postgraduate Press Inc.; 2006. p. 
106.

61. Füzéki E, Groneberg DA, Banzer W. Physical activity during COVID-19 induced lockdown: recommendations. J Occup Med Toxicol. 2020;15(1).

62. Peluso MAM, Guerra de Andrade LHS. Physical activity and mental health: the association between exercise and mood. Vol. 60, Clinics (São Paulo, Brazil). Faculdade de Medicina / USP; 2005. p. 61-70.

63. Rodriguez-Ayllon M, Cadenas-Sánchez C, Estévez-López F, Muñoz NE, Mora-Gonzalez J, Migueles JH, et al. Role of Physical Activity and Sedentary Behavior in the Mental Health of Preschoolers, Children and Adolescents: A Systematic Review and Meta-Analysis. Vol. 49, Sports Medicine. Springer International Publishing; 2019. p. 1383-410.

64. Wu X, Tao S, Zhang Y, Zhang S, Tao F. Low physical activity and high screen time can increase the risks of mental health problems and poor sleep quality among Chinese college students. Tian J, editor. PLoS One. 2015;10(3):e0119607.

65. Bell SL, Audrey S, Gunnell D, Cooper A, Campbell R. The relationship between physical activity, mental wellbeing and symptoms of mental health disorder in adolescents: A cohort study. Int J Behav Nutr Phys Act. 2019;16(1):138.

66. Maugeri G, Castrogiovanni P, Battaglia G, Pippi R, D’Agata V, Palma A, et al. The impact of physical activity on psychological health during Covid-19 pandemic in Italy. Heliyon. 2020;6(6):e04315.

67. Dunton GF, Do B, Wang SD. Early effects of the COVID-19 pandemic on physical activity and sedentary behavior in children living in the U.S. BMC Public Health. 2020;20(1):1351.

68. Di Stefano V, Battaglia G, Giustino V, Gagliardo A, D’Aleo M, Giannini O, et al. Significant reduction of physical activity in patients with neuromuscular disease during COVID-19 pandemic: the long-term consequences of quarantine. J Neurol. 2020 
Table 1. Socio-demographic characteristics of participants by levels of anxiety

\begin{tabular}{|c|c|c|c|c|c|}
\hline \multirow[t]{2}{*}{ Characteristic } & \multicolumn{4}{|c|}{ Levels of anxiety, $N=273$} & \multirow[t]{2}{*}{$P$-value } \\
\hline & $\begin{array}{l}\text { No anxiety } \\
\mathrm{n}=65(23.8 \%)\end{array}$ & $\begin{array}{l}\text { Mild anxiety } \\
\mathrm{n}=94(34.4 \%)\end{array}$ & $\begin{array}{l}\text { Moderate anxiety } \\
\mathrm{n}=68(24.9 \%)\end{array}$ & $\begin{array}{l}\text { Severe anxiety } \\
n=46(16.9 \%)\end{array}$ & \\
\hline Age median (IQR) & $24(23-28)$ & $23.5(22-25)$ & $23(22-26.5)$ & $24(22-28)$ & $0.195^{\mathrm{a}}$ \\
\hline \multicolumn{6}{|l|}{$\operatorname{Sex}, \mathrm{n}(\%)$} \\
\hline male & $31(23.5)$ & $49(37.1)$ & $30(22.7)$ & $22(16.7)$ & $0.791^{\mathrm{b}}$ \\
\hline female & $34(24.1)$ & 45 (31.9) & $38(26.9)$ & $24(17)$ & \\
\hline \multicolumn{6}{|c|}{ Marital status, n (\%) } \\
\hline single & $48(21.3)$ & $85(37.8)$ & $57(25.3)$ & $35(15.6)$ & \\
\hline married & $17(36.2)$ & $9(19.2)$ & $11(23.4)$ & $10(21.3)$ & $0.024^{\mathrm{c}}$ \\
\hline \multicolumn{6}{|c|}{ Year of study, n (\%) } \\
\hline Second & $4(13.3)$ & $8(26.7)$ & $10(33.3)$ & $8(26.7)$ & \\
\hline Third & $26(23)$ & $36(31.9)$ & $32(28.3)$ & $19(16.8)$ & \\
\hline Fourth & $17(21)$ & $30(37.5)$ & $17(21.2)$ & $16(20)$ & \\
\hline Fifth & $18(36)$ & $20(40)$ & $9(18)$ & $3(6)$ & $0.102^{\mathrm{c}}$ \\
\hline \multicolumn{6}{|l|}{ Employed, n (\%) } \\
\hline Yes & $23(29.9)$ & $21(27.3)$ & $16(20.8)$ & $17(22.1)$ & \\
\hline No & $42(21.4)$ & $73(37.2)$ & $52(26.5)$ & $29(14.8)$ & $0.128^{\mathrm{b}}$ \\
\hline \multicolumn{6}{|l|}{ Residence, n (\%) } \\
\hline Urban & $44(28.2)$ & $59(37.8)$ & $30(19.2)$ & $23(14.7)$ & \\
\hline Rural-urban & $18(27.3)$ & $16(24.2)$ & $18(27.3)$ & $14(21.2)$ & \\
\hline Rural & $3(5.9)$ & $19(37.3)$ & $20(39.2)$ & $9(17.7)$ & $0.005^{\mathrm{b}}$ \\
\hline \multicolumn{6}{|c|}{$\begin{array}{l}\text { Living with parents, } n \\
(\%)\end{array}$} \\
\hline Yes & $34(19.1)$ & $70(39.3)$ & $47(26.4)$ & $27(15.2)$ & \\
\hline No & $31(32.6)$ & $24(25.3)$ & $21(22.1)$ & $19(20)$ & $0.022^{\mathrm{b}}$ \\
\hline
\end{tabular}

Key: ${ }^{a}=$ Kruskal Wallis test, ${ }^{b}=$ Pearson chi-square test, ${ }^{c}=$ Fisher's exact test, IQR-interquartile range 
medRxiv preprint doi: https://doi.org/10.1101/2021.01.11.21249547; this version posted January 13, 2021. The copyright holder for this preprint (which was not certified by peer review) is the author/funder, who has granted medRxiv a license to display the preprint in perpetuity.

It is made available under a CC-BY-NC 4.0 International license .

Table 2. Academic life, social networks and family support of participants by levels of anxiety

\begin{tabular}{|c|c|c|c|c|c|}
\hline \multirow[t]{2}{*}{ Characteristic } & \multicolumn{4}{|c|}{ Levels of anxiety, $N=273$} & \multirow[t]{2}{*}{$P$-value } \\
\hline & $\begin{array}{l}\text { No anxiety } \\
n=65(23.8 \%)\end{array}$ & $\begin{array}{l}\text { Mild anxiety } \\
\mathrm{n}=94(34.4 \%)\end{array}$ & $\begin{array}{l}\text { Moderate anxiety } \\
\mathrm{n}=68(24.9 \%)\end{array}$ & $\begin{array}{l}\text { Severe anxiety } \\
n=46(16.9 \%)\end{array}$ & \\
\hline \multicolumn{6}{|c|}{ Feeling helpless, n (\%) } \\
\hline Yes & $29(15.3)$ & $64(33.9)$ & $58(30.7)$ & $38(20)$ & $<0.0001^{\mathrm{b}}$ \\
\hline No & $36(42.9)$ & $30(35.7)$ & $10(11.9)$ & $8(9.5)$ & \\
\hline \multicolumn{6}{|l|}{ Time resting, $\mathrm{n}(\%)$} \\
\hline Has increased & $34(28.1)$ & $44(36.6)$ & $25(20.7)$ & $18(15)$ & \\
\hline Has reduced & $11(10.5)$ & $37(35.2)$ & $34(32.4)$ & $23(21.9)$ & $0.001^{\mathrm{b}}$ \\
\hline Remain same & $20(42.6)$ & $13(27.7)$ & $9(19.1)$ & $5(10.6)$ & \\
\hline \multicolumn{6}{|l|}{ Time relaxing, n (\%) } \\
\hline Has increased & $25(26.6)$ & $38(40.4)$ & $18(19.2)$ & $13(13.8)$ & $0.002^{\mathrm{b}}$ \\
\hline Has reduced & $22(15.7)$ & $47(33.6)$ & $44(31.4)$ & $27(19.3)$ & \\
\hline Remain same & $18(46.2)$ & $9(23.1)$ & $6(15.4)$ & $6(15.4)$ & \\
\hline \multicolumn{6}{|l|}{ Time exercise, n (\%) } \\
\hline Has increased & $16(22.9)$ & $32(45.7)$ & $11(15.7)$ & $11(15.7)$ & $0.017^{\mathrm{b}}$ \\
\hline Has reduced & $27(21.8)$ & $35(28.2)$ & $33(26.6)$ & $29(23.4)$ & \\
\hline Remain same & $22(27.9)$ & $27(34.2)$ & $24(30.4)$ & $6(7.6)$ & \\
\hline \multicolumn{6}{|c|}{ performance, n (\%) } \\
\hline Has increased & $11(55)$ & $3(15)$ & $2(10)$ & $4(20)$ & $<0.0001^{\mathrm{c}}$ \\
\hline Has reduced & $38(17.2)$ & $83(37.6)$ & $62(28.1)$ & $38(17.2)$ & \\
\hline Remain same & $16(50)$ & $8(25)$ & $4(12.5)$ & $4(12.5)$ & \\
\hline \multicolumn{6}{|c|}{ Family Support, n (\%) } \\
\hline Has increased & $18(20.9)$ & $28(32.6)$ & $26(30.2)$ & $14(16.3)$ & $<0.0001^{\mathrm{b}}$ \\
\hline Has reduced & $20(17)$ & $43(36.4)$ & $28(23.7)$ & $27(22.9)$ & \\
\hline Remain same & $26(38.8)$ & $23(34.3)$ & $13(19.4)$ & $5(7.5)$ & \\
\hline \multicolumn{6}{|c|}{ Friends support, n (\%) } \\
\hline Has increased & $7(20)$ & $12(34.3)$ & $11(31.4)$ & $5(14.3)$ & $0.026^{\mathrm{b}}$ \\
\hline Has reduced & $36(19.8)$ & $61(33.5)$ & $48(26.4)$ & $37(20.3)$ & \\
\hline Remain same & $22(39.3)$ & $21(37.5)$ & $9(16.1)$ & $4(7.1)$ & \\
\hline \multicolumn{6}{|l|}{$\begin{array}{l}\text { Prefer E-learning, } \\
\mathbf{n}(\%)\end{array}$} \\
\hline Yes & $21(36.2)$ & $15(25.9)$ & $12(20.7)$ & $10(19.2)$ & \\
\hline No & $44(20.5)$ & $79(36.7)$ & $56(26.1)$ & $36(16.7)$ & $0.077^{\mathrm{b}}$ \\
\hline \multicolumn{6}{|c|}{ Steady income, $n(\%)$} \\
\hline Yes & $30(34.9)$ & $27(31.4)$ & $14(16.3)$ & $15(17.4)$ & \\
\hline No & $35(18.7)$ & $67(35.8)$ & $54(28.9)$ & 31 (16.6) & $0.014^{\mathrm{b}}$ \\
\hline
\end{tabular}

Key: ${ }^{a}=$ Kruskal Wallis test, ${ }^{b}=$ Pearson chi-square test, ${ }^{c}=$ Fisher's exact test, IQR-interquartile range 
medRxiv preprint doi: https://doi.org/10.1101/2021.01.11.21249547; this version posted January 13, 2021. The copyright holder for this preprint (which was not certified by peer review) is the author/funder, who has granted medRxiv a license to display the preprint in perpetuity.

It is made available under a CC-BY-NC 4.0 International license .

Table 3: Factors affecting the mental health of undergraduate pharmacy students

Characteristic

No_anxiety vs. (mild, moderate $\& \quad$ No_anxiety $\&$ mild anxiety vs. ( severe anxiety)
Comparison

moderate \& severe anxiety)
No_anxiety, mild \& moderate anxiety vs. (severe anxiety)

\begin{tabular}{|c|c|c|c|c|c|c|c|c|c|}
\hline & $\mathbf{B}_{1}$ & $\mathrm{OR}_{1}$ & CI (P-value) & $\mathbf{B}_{2}$ & $\mathrm{OR}_{2}$ & CI (P-value) & $\mathbf{B}_{3}$ & $\mathrm{OR}_{3}$ & CI (P-value) \\
\hline Age (years) & 0.04 & 1.04 & $0.92-1.09(0.142)$ & 0.04 & 1.04 & $0.92-1.09(0.142)$ & 0.04 & 1.04 & $0.92-1.09(0.142)$ \\
\hline \multicolumn{10}{|l|}{ Family Care } \\
\hline Increased & & ref & & & ref & & & ref & \\
\hline Reduced & 0.82 & 2.27 & $1.09-4.74(0.029)$ & 0.82 & 2.27 & $1.09-4.74(0.029)$ & 0.82 & 2.27 & $1.09-4.74(0.029)$ \\
\hline Remained same & 0.03 & 1.03 & $0.57-1.87(0.926)$ & 0.03 & 1.03 & $0.57-1.87(0.926)$ & 0.03 & 1.03 & $0.57-1.87(0.926)$ \\
\hline
\end{tabular}

Mental health attention

\begin{tabular}{lccccccccc}
\hline Increased & \multicolumn{2}{c}{ ref } & \multicolumn{3}{c}{ ref } & & \multicolumn{2}{c}{ ref } \\
& & & & & & & \\
Reduced & -0.09 & 0.92 & $0.46-1.83(0.810)$ & -0.09 & 0.92 & $0.46-1.83(0.810)$ & -0.09 & 0.92 & $0.46-1.83(0.810)$ \\
& & & & & & & & \\
\hline Remained same & -1.09 & 0.33 & $0.18-0.62(0.001)$ & -1.09 & 0.33 & $0.18-0.62(0.001)$ & -1.09 & 0.33 & $0.18-0.62(0.001)$
\end{tabular}

Year of study

\begin{tabular}{lccccccccc}
\hline Second & \multicolumn{3}{c}{ ref } & & & & \\
& & & & & & \\
\hline Third & -0.48 & 0.62 & $0.27-1.40(0.246)$ & -0.48 & 0.62 & $0.27-1.40(0.246)$ & -0.48 & 0.62 & $0.27-1.40(0.246)$ \\
& & & & & & & & \\
\hline Fourth & -0.43 & 0.65 & $0.28-1.53(0.328)$ & -0.43 & 0.65 & $0.28-1.53(0.328)$ & -0.43 & 0.65 & $0.28-1.53(0.328)$ \\
& & & & & & & & & \\
\hline Fifth & -1.12 & 0.33 & $0.13-0.84(0.020)$ & -1.12 & 0.33 & $0.13-0.84(0.020)$ & -1.12 & 0.33 & $0.13-0.84(0.020)$
\end{tabular}

Time on resting

\begin{tabular}{|c|c|c|c|c|c|c|c|c|c|}
\hline Increased & & ref & & ref & & & ref & & \\
\hline Reduced & 0.74 & 2.10 & $1.26-3.50(0.005)$ & 0.74 & 2.10 & $1.26-3.50(0.005)$ & 0.74 & 2.10 & $1.26-3.50(0.005)$ \\
\hline Remained same & 0.69 & 1.99 & $0.94-4.20(0.073)$ & 0.69 & 1.99 & $0.94-4.20(0.073)$ & 0.69 & 1.99 & $0.94-4.20(0.073)$ \\
\hline
\end{tabular}

Feeling helpless

\begin{tabular}{llllllllll}
\hline Yes & ref & & & ref & ref & & ref & ref & \\
\hline No & -0.87 & 0.42 & $\begin{array}{l}0.23-0.75 \\
(0.0004)\end{array}$ & -0.87 & 0.42 & $0.23-0.75(0.0004)$ & -0.87 & 0.42 & $0.23-0.75(0.0004)$ \\
\hline
\end{tabular}

Academic work

\begin{tabular}{lcclcccccc}
\hline Increased & ref & ref & & ref & ref & & ref & ref \\
& & & & & & \\
\hline Reduced & 2.28 & 9.81 & $\begin{array}{l}3.12-30.88 \\
(<0.0001)\end{array}$ & 1.40 & 4.05 & $1.23-13.28(0.021)$ & 0.73 & 2.07 & $0.57-7.45(0.266)$ \\
& & & & & & & \\
\hline Remained same & 0.93 & 2.54 & $0.75-8.63(0.136)$ & 0.93 & 2.53 & $0.75-8.63(0.136)$ & 0.93 & 2.54 & $0.75-8.63(0.136)$
\end{tabular}


medRxiv preprint doi: https://doi.org/10.1101/2021.01.11.21249547; this version posted January 13, 2021. The copyright holder for this preprint (which was not certified by peer review) is the author/funder, who has granted medRxiv a license to display the preprint in perpetuity.

\author{
It is made available under a CC-BY-NC 4.0 International license .
}

Wald test of parallel lines assumption for the final model: chi2 $=29.27, \mathrm{df}=32, P=0.606$, Goodness-of-fit test of overall model (Likelihood Ratio): Chi-square $=95.77, \mathrm{df}=19$, p-value $<0.0001$, Pseudo $R^{2}=0.1308$ 